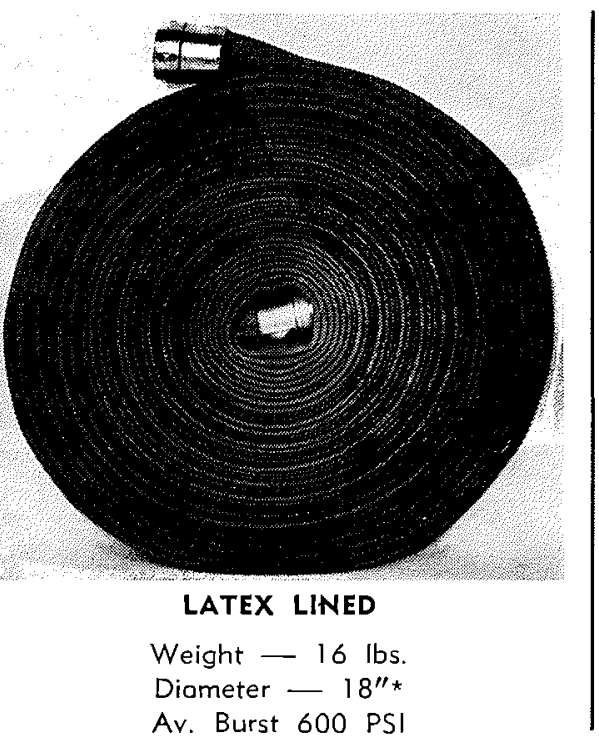

NEW ALL PURPOSE
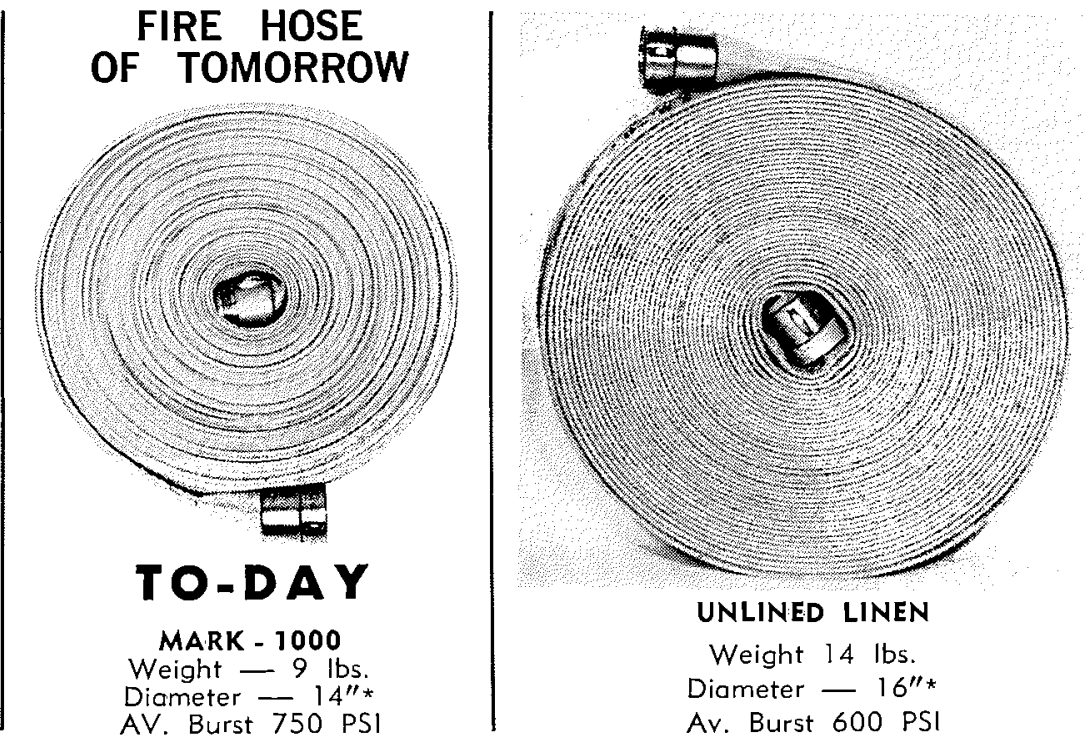

Would you believe the three types shown are $100 \mathrm{ft}$. rolls? Which would you prefer to carry into the woods?

- Lined to reduce friction - more water and pressure at the fire - Self-protecting - will resist flame-up when exposed to elevated temperatures - Flexible - can be dried, rolled and stored same day after use. "(Without couplings)



\section{advertisers index}

Fig. 1. Fisherman and camper-caused fires compared to total

Austin Lumber 123

Ben Meadows 80

Canadian Forestry Education 123

Canadian Forestry Equipment O.B.C.

E. S. Fellows

Forano Limited

I.F.C.

Forestal

Forestry Suppliers Inc.

Imperial Life

Industrial Forestry Service Ltd.

Nelson Paint Co.

C. D. Schultz \& Co. Ltd.

Sir Sanford Fleming College

Wajax

\section{SIR SANDFORD FLEMING COLLEGE OF APPLIED ARTS AND TECHNOLOGY}

\section{NATURAL RESOURCES DIVISION, LINDSAY}

Applications are being accepted for teaching positions

Forest Mensuration (two positions)

Surveying

Photogrammetry and Cartography

Silviculture and Soils

Government and Law, Economics

English and Communications

Fish and Wildlife Management

The above positions require appropriate University degrees, plus at least two years acceptable experience. An advanced degree is an advantage, but not a necessity.

\section{Descriptive Dendrology}

The above position requires a Forest Technician Diploma with at least six years acceptable experience.

SALARY RANGE:



Written replies sould be directed to: The President,

SIR SANDFORD FLEMING COLLEGE, P. O. Box 653, Peterborough, Ontario. 